\title{
Cardiovascular risks in chronic kidney disease pediatric patients (Review)
}

\author{
JING TIAN, LING NIU and XINJIANG AN \\ Department of Pediatric Internal Medicine, Xuzhou Children's Hospital, Xuzhou, Jiangsu 221002, P.R. China
}

Received May 15, 2017; Accepted September 14, 2017

DOI: $10.3892 /$ etm.2017.5117

\begin{abstract}
One of the common factors for the premature death in children is advanced chronic kidney disease (CKD). Most often cardiovascular disease (CVD) is the reason for mortality. The cardiovascular (CV) morbidity starts early in the disease process and renal transplanted children (CKD-T) are also at risk. The present review is focused on the current views of the cardiovascular risks during CKD in pediatric patients. Variable data sources for the latest literature collection were explored which mainly included PubMed and Google Scholar. The most important risk factors for subclinical CVD were a young age, elevated BMI and systolic blood pressure z-scores as well as a low GFR and present albuminuria. Increasing blood pressure and BMI over follow-up were also important cardiac risk factors longitudinally. The present review concludes that altered cardiac function and remodeling are a concurrent part of the CKD process, start early in the disease development, and persist after renal transplantation. The findings suggest that children with CKD or CKD-T are at high risk for future CVD where younger patients with elevated BMI and slightly increased blood pressures, as well as present albuminuria, are those at greatest risk, thus indicating targets for future interventions.
\end{abstract}

\section{Contents}

1. Introduction

2. Epidemiology of CKD

3. Epidemiology of CVD in CKD

4. Risk factors and risk markers

5. Conclusions

Correspondence to: Dr Xinjiang An, Department of Pediatric Internal Medicine, Xuzhou Children's Hospital, 18 Sudibei Road, Xuzhou, Jiangsu 221002, P.R. China

E-mail: anxinjian001@163.com

Key words: CKD, CKD-T, renal transplant, chronic kidney disease, pediatric patient

\section{Introduction}

An irreversible damage to kidneys that usually result in end stage renal disease (ESRD) is termed as chronic kidney disease (CKD) (1). The renal replacement therapy is the need of the hour as CKD affected patients are on continuous rise (2). These therapeutic options include dialysis or renal transplantation1. Renal transplantation improves both morbidity and survival rates, but the risks for disease and early death still remain higher than in the general age-matched population (3). CKD affected pediatric patients are less in comparison to adults but the prevalence of RRT in children has increased in the last decades. A total number of 9,921 children with RRT in the US in 2013 and 3,595 children aged 0-14 years with RRT in Europe in 2011, indicates that this is a significant medical problem (4).

The first pediatric renal transplant was performed over 50 years ago, and there have been significant improvements in post-transplant survival and care since then. In addition, advances in surgical techniques have allowed successful transplantations to be performed in smaller (and younger) children. However, mortality rates are still high, with a major cause being attributed to cardiovascular disease (CVD) (5). In the last decade new echocardiographic techniques have enabled the analysis of subtle subclinical changes in cardiac geometry and function, shown to predict future CV events and death in both the general population and adult CKD patients (6). However, long-term studies of subclinical CV morbidity in pediatric CKD are scarce.

\section{Epidemiology of CKD}

CKD is in simple words an irreversible loss of kidney function over time. The main causes of CKD in adults are hypertension and diabetes, constituting two-thirds of all cases. In pediatric patients, the etiology is very different from that in adults (7). The pediatric nephrology registry from North America (NAPRTCS) includes more than 7,000 children and adolescents registered between 1994 and 2008. According to this registry, 58\% of pediatric CKD cases are due to congenital causes, divided into congenital abnormalities of the kidney and urinary tract (CAKUT: 48\%) and hereditary nephropathies (10\%). Glomerulonephritis accounted for $14 \%$, cystic kidney disease 5\% and Hemolytic Uremic Syndrome (HUS) together with ischemic renal failure composed $4 \%$ (8). In two large 
European registries from Italy and Belgium, similar distributions are reported $(9,10)$.

Regarding the cause of CKD in pediatric patients with RRT, the same trends are observed in the ESPN/ERA-EDTA registry (4). This is a European registry formed in 2007 that includes 37 countries and children with RRT aged 0-14 years. For nine of the countries, data on ages 0-19 years are also available. In their latest study, CAKUT was the dominant cause $(41 \%)$ of pediatric RRT in Europe. The second largest cause was glomerulonephritis (15\%), followed by cystic kidney disease $(10 \%)$ and hereditary nephropathies (7\%).

\section{Epidemiology of CVD in CKD}

In adults with RRT, arrhythmias and cardiac arrest was the most common cause of mortality, constituting $37 \%$ of all deaths according to the last report from USRDS (11). Atherosclerotic heart disease composed the majority of all CVD in patients over the age of 44 years, while in-patient aged 22-44 years, congestive heart failure was mainly responsible for CKD. In patients aged 0-21 years, congestive heart failure constituted $19 \%$ of all CVD, followed by peripheral arterial disease (17\%). In contrast to the aged population with RRT, this young cohort rarely demonstrated atherosclerotic heart disease $(<4 \%)$. In a large population based cohort study, Go et al examined more than 1.1 million adults, and identified a gradual increase in hazard ratios for adverse $\mathrm{CV}$ events as renal function decreased (12). Based on these observations pediatric CKD patients are put in the highest risk category (13).

\section{Risk factors and risk markers}

The risk factors are characteristics that could be measured in order to estimate well-defined outcomes. On the other hand, risk markers are biological indicators of disease development. Even though the causality of the following CV risk factors in CKD listed below is not fully established, they are often classified as just traditional or non-traditional CV risk factors. Non-traditional risk factors are, in the CKD population, often referred to as uremia-related risk factors. In 2011, the Chronic Kidney Disease in Children (CKiD) study, an observational cohort study of 586 children aged 1-16 years with CKD stages 2-4, published comprehensive data on CV risk factors. Overall, $39 \%$ of participants had at least one risk factor, $22 \%$ had two risk factors and $13 \%$ had three present risk factors (14). The number of prevalent risk factors increases as CKD progresses, and is highest in children on maintenance dialysis. Following kidney transplantation the prevalence of these traditional risk factors remains high. However, Kaidar et al recently showed that in 77 renal transplant patients the number of risk factors present decreased progressively following renal transplantation to the last follow-up visit (on average seven years) (15).

Hypertension and CKD. Hypertension in pediatric CKD results from volume expansion and increased vascular resistance, which develops as renal function deteriorates. Controlled hypertension is defined as the need of antihypertensive medications in order to regulate blood pressure levels to $<95$ th percentile. Hypertension is confirmed risk factor for CVD (16). In children with CKD, hypertension is associated with deterioration in renal, cardiac and vascular functions (17-19). In data from the CKD cohort, $21 \%$ were normotensive, $37 \%$ had elevated blood pressure and $42 \%$ had controlled hypertension (20). In the same cohort, $14 \%$ and had uncontrolled systolic hypertension and $13 \%$ uncontrolled diastolic hypertension using office blood pressures (21). High BMI and elevated levels of proteinuria were important risk factors for a longitudinally increasing blood pressure. Equally, ambulatory blood pressure (ABP) measurements revealed that $19 \%$ had masked hypertension and $13 \%$ confirmed hypertension. Further, a high variability in mean systolic ABP was seen, but also in night diastolic ABP in hypertensive children (22).

The prevalence of hypertension increased in the immediate and short-term following renal transplantation and was $52 \%$ two months after transplantation, and decreased to $27.5 \%$ after six months, and $22 \%$ two years after transplantation (15). At the same time points, 54.8, 38 and $37.7 \%$ of patients were treated with antihypertensive medication. In another study, $27.9 \%$ of children were normotensive six months after renal transplantation and not treated with antihypertensive drugs. Of these non-hypertensive patient post-transplants, $49.3 \%$ became hypertensive and commenced antihypertensive medication during the follow-up of two years (23). Still, long-term prevalence of uncontrolled hypertension 7-18 years after renal transplantation was only $12-14 \%$ (24).

Dyslipidemia and CKD. Dyslipidemia in CKD is characterized by increased levels of plasma triglycerides (TG) and triglyceride-rich lipoproteins, as well as decreased high density lipoprotein cholesterol (HDL) and apolipoprotein A. Chylomicron remnants and VLDL accumulate in CKD patients due to increased production and impaired catabolism (25). The KDIGO recently published guidelines with cut-offs for acceptable, borderline high and high levels for cholesterol, LDL and non-LDL in children (26). The potential impact of dyslipidemia on CVD in the general population is profound. Indeed, elevated lipid levels in children without renal disease present a risk factor for later CVD (27). However, the relative risk of CVD from dyslipidemia in children with CKD compared to the general pediatric population is not known.

The dyslipidemia with CKD is commonly observed in children. Dyslipidemia is more common and severe in patients with glomerular disease and proteinuria, as well as in late stage CKD (28). Specifically, elevated levels of triglycerides and non-HDL, as well as the use of lipid lowering drugs, have been reported in $44 \%$ of children with CKD stages 2-4. As GFR declines, both triglyceride and cholesterol levels increase (29). The hypercholesterolemia frequency is high in pediatric renal transplant patients (30). After seven years the prevalence was 33 and $13 \%$, respectively. The major cause of dyslipidemia in this patient group is not only progressive loss in renal function, but can also be attributed to medications used; particularly corticosteroids, cyclosporine and sirolimus (31).

Abnormal glucose metabolism. In CKD, glucose intolerance is primarily a result of impaired tissue sensitivity to insulin with several possible causes discussed in the literature (32). Glucose intolerance involves impaired fasting glucose (IFG), impaired glucose tolerance (IGT) and diabetes mellitus. The American Diabetes Association (ADA) and WHO use different 
definitions of these abnormalities, which generates confusion when comparing studies. The cut-off for glucose to define IFG ranges from 5.6 (ADA) to 6.1 (WHO) mmol/l (33). While other measures of insulin resistance (intravenous glucose tolerance test and glucose clamp technique) are more robust, they are invasive and usually not possible to perform in routine clinical check-ups. Alterations in glucose and insulin metabolism are important contributors of CVD and might also be of importance in adult CKD and CKD-T patients. For example, 'new-onset diabetes after kidney transplantation' (NODAT) is associated with impaired renal survival and an increased CV morbidity and mortality in adult patients (34). Very few data are available for the impact of abnormal glucose metabolism in pediatric CKD.

$I G F, I G T$ and $C K D$. IFG and IGT are common in pediatric $\mathrm{CKD}$, including dialysis patients. Using the ADA definitions, $35 \%$ of pediatric non-dialysis CKD patients exhibit either IFG or IGT (35). While the prevalence for hyperinsulinemia varies between studies of pediatric CKD stage 2-4 (9-33\%), insulin resistance reveals similar prevalence (16-19\%) (36). Moreover, using the WHO definition for IFG, overall $21 \%$ of pediatric patients in the CKiD cohort had abnormal glucose metabolism defined as IFG, hyperinsulinemia or insulin resistance.

Anemia and CKD. Anemia in CKD is predominantly caused by erythropoietin deficiency, but other factors such as acidosis, inflammation and malnutrition related to uremia contribute as well (37). Due to various definitions of anemia used historically (38), comparisons between studies have sometimes been troublesome. Following guidelines recently presented by KDIGO with cut-offs to define anemia in children at different ages, this issue is hopefully transient (39). Further, in pediatric CKD-T patients lower hemoglobin was associated with increased risk of death, and also graft loss (40). Anemia is present during early stages of CKD and is often poorly controlled, especially in children with advanced CKD35. Moreover, anemia sometimes remains after renal transplantation. Thus, $30 \%$ of pediatric patients at two months after transplantation and $18 \%$ after seven years are anemic. In a very recent large multicenter study, the prevalence of anemia, ranged from 7.8 to $49.8 \%$ depending on the cut-off used. When the definitions of anemia encompassed erythropoietin treatment, the prevalence increased to 16.3 and $58.1 \%$. Hemoglobin levels were associated with pre-transplant care (pre-emptive transplantation vs. previous dialysis treatment), graft function and antihypertensive and immunosuppressive medications.

Chronic inflammation and $C K D$. The chronic inflammation is often seen associated with CKD and RRT. There is an inverse correlation between GFR and level of inflammatory cytokines as well as a positive correlation between albuminuria and inflammation (41). Different biomarkers of inflammation appear to have varying predictive values. For example, Interleukin-6 (IL-6) predicts all-cause and CV mortality more accurately than C-reactive protein (CRP) and other cytokines (42). The postulated mechanism of inflammation in CVD is that chronic inflammation promotes vascular calcification and endothelial dysfunction (43). While chronic inflammation is present in pediatric CKD and dialysis patients (42), its role in this group remains conflicting (43). Inflammation is also discussed as a potential CV risk factor in pediatric CKD-T patients, but very few studies are available (44). The significance of inflammation in this group, receiving a variety of immunosuppressive agents is difficult to interpret.

Albuminuria and $C K D$. Albuminuria means excessive loss of albumin in the urine due to abnormalities in kidney functions. The presence of persistent albuminuria is an early sign of renal damage and is closely related to the progression of CKD in children (45). As for several other CV risk factors mentioned previously, comparing studies on albuminuria and proteinuria is troublesome as they often use different definitions. Microalbuminuria is often defined as spot sample urinary albumin of $30-300 \mathrm{mg} / \mathrm{l}$ and above this limit is macro-albuminuria. In addition to its role as a marker for CKD risk, it is now widely accepted that albuminuria is an independent predictor of CV morbidity and mortality across various populations (46). The pathophysiological link between albuminuria and CVD are related especially in relation to endothelial dysfunction (47).

Albuminuria is common in pediatric CKD and in the CKiD cohort, $71 \%$ had an elevated urinary protein to creatinine ratio. Approximately $20 \%$ of these patients had nephrotic range proteinuria. Longitudinal pediatric studies have shown that albuminuria is an independent predictor for CKD progression and increasing blood pressures (48). The rate of albuminuria usually falls after transplantation, and persistence or late appearance of albuminuria represents graft injury with the mechanism being multifactorial (49). In a small study of 53 renal transplanted children, $47 \%$ had pathologic urinary protein to creatinine ratio (50).

Abnormal mineral metabolism and CKD. In mineral metabolism there is a complex interaction between the kidneys, the parathyroid gland, the gastrointestinal tract, and the skeleton. In children with CKD, these mechanisms are often disrupted. Phosphorus retention begins during the earliest stages of CKD is also linked with the development of hyperparathyroidism. Ongoing research has identified other factors of importance in the regulation of phosphorus balance; Fibroblast growth factor 23 (FGF23) with Klotho reduce the expression of sodium phosphate co-transporters $(\mathrm{NaPi} 2 \mathrm{a} / \mathrm{c})$ in the proximal renal tubule in the kidney to induce phosphaturia, similar to PTH. In more advanced stages of CKD, this adaptation becomes less successful, and as a result hyperphosphatemia is more commonly found (51). The role of CKD-MBD on mortality is not fully clear. Low levels of 25-vitamin D are associated with all-cause and CV mortality in adult hemodialysis patients (52), and are associated with worsened cardiac morbidity and progressive renal failure in pediatric CKD (53). However, recent meta-analyses have not been able to prove that vitamin D supplementation affect mortality or CV risk in adult CKD patients, with or without RRT (54). Further, while hyperphosphatemia also has been independently associated with mortality in adult CKD, it is clear that FGF23 increases as CKD progresses, and becomes maladaptive and possibly contributes to cardiac remodeling independent of phosphate levels (55). In addition, while FGF23 increase, Klotho decrease as the renal function deteriorates (56). Low levels of soluble Klotho has been found 
to be involved in vascular calcification in CKD and other populations, but has not been linked to increased mortality (57). However, the numbers of studies are few.

Abnormal mineral metabolism is often observed in pediatric CKD patients. Although children with early stage CKD generally have no signs or symptoms of bone abnormalities, laboratory testing might already show decreased 25-vitamin D and elevated PTH (58). Current treatments focus on suppression of PTH with vitamin D supplementations. Subtle signs of bone osteodystrophy may begin in CKD stage 3 with muscle pain, weakness and bone deformations. In a small report of pediatric CKD, bone biopsy demonstrated increased bone turnover in 0 , 13 and $29 \%$ and defective mineralization in 29,42 and $79 \%$ in CKD stage 2, 3 and 4/5 (before dialysis) respectively (59). FGF23 levels increase as CKD progresses from stage 1 to 5 in children with the most marked elevation in advanced CKD (60). FGF23 is elevated also in CKD-T children (61), in which hyperparathyroidism is also common (32\% two months after transplantation and 18\% after seven years). Levels of soluble Klotho in pediatric CKD-T have only been published in very few previous studies $(61,62)$.

\section{Conclusions}

The present review concludes that altered cardiac function and remodeling are a concurrent part of the CKD process, start early in the disease development, and persist after renal transplantation.

\section{References}

1. Yokomichi H, Nagai A, Hirata M, Kiyohara Y, Muto K, Ninomiya T, Matsuda K, Kamatani Y, Tamakoshi A, Kubo M, et al; BioBank Japan Cooperative Hospital Group: Survival of macrovascular disease, chronic kidney disease, chronic respiratory disease, cancer and smoking in patients with type 2 diabetes: BioBank Japan cohort. J Epidemiol 27: S98-S106, 2017.

2. Wang C, Lv LS, Huang H, Guan J, Ye Z, Li S, Wang Y, Lou T and Liu X: Initiation time of renal replacement therapy on patients with acute kidney injury: A systematic review and meta-analysis of 8179 participants. Nephrology (Carlton) 22: 7-18, 2017.

3. Laskin BL, Mitsnefes MM, Dahhou M, Zhang X and Foster BJ: The mortality risk with graft function has decreased among children receiving a first kidney transplant in the United States. Kidney Int 87: 575-583, 2015.

4. Chesnaye N, Bonthuis M, Schaefer F, Groothoff JW, Verrina E, Heaf JG, Jankauskiene A, Lukosiene V, Molchanova EA, Mota C, et al; ESPN/ERA-EDTA registry: Demographics of paediatric renal replacement therapy in Europe: A report of the ESPN/ ERA-EDTA registry. Pediatr Nephrol 29: 2403-2410, 2014.

5. McDonald SP and Craig JC; Australian and New Zealand Paediatric Nephrology Association: Long-term survival of children with end-stage renal disease. N Engl J Med 350: 2654-2662, 2004.

6. Mogelvang R, Biering-Sørensen T and Jensen JS: Tissue Doppler echocardiography predicts acute myocardial infarction, heart failure, and cardiovascular death in the general population. Eur Heart J Cardiovasc Imaging 16: 1331-1337, 2015.

7. Hruska KA, Sugatani T, Agapova O and Fang Y: The chronic kidney disease - mineral bone disorder (CKD-MBD): Advances in pathophysiology. Bone 100: 80-86, 2017.

8. Martz K and Stablein DM (eds): North American Pediatric Renal Transplant Cooperative Studies (NAPRTCS): Annual Report. The EMMES Coporation, Rockville, MD, 2008. https://web.emmes. $\mathrm{com} / \mathrm{study} / \mathrm{ped} / \mathrm{ann}$ lrept/Annual\%20Report\%20-2008.pdf.

9. Mong Hiep TT, Ismaili K, Collart F, Van Damme-Lombaerts R, Godefroid N, Ghuysen MS, Van Hoeck K, Raes A, Janssen F and Robert A: Clinical characteristics and outcomes of children with stage 3-5 chronic kidney disease. Pediatr Nephrol 25: 935-940, 2010.
10. Ardissino G, Daccò V, Testa S, Bonaudo R, Claris-Appiani A, Taioli E, Marra G, Edefonti A and Sereni F; ItalKid Project: Epidemiology of chronic renal failure in children: Data from the ItalKid project. Pediatrics 111: e382-e387, 2003.

11. Saran R, Li Y, Robinson B, Abbott KC, Agodoa LY, Ayanian J, Bragg-Gresham J, Balkrishnan R, Chen JL, Cope E, et al: US Renal Data System 2015 Annual Data Report: Epidemiology of Kidney Disease in the United States. Am J Kidney 67 (Suppl 1): S1-S305, 2016.

12. Go AS, Chertow GM, Fan D, McCulloch CE and Hsu CY: Chronic kidney disease and the risks of death, cardiovascular events, and hospitalization. N Engl J Med 351: 1296-1305, 2004.

13. Kavey RE, Allada V, Daniels SR, Hayman LL, McCrindle BW, Newburger JW, Parekh RS and Steinberger J; American Heart Association Expert Panel on Population and Prevention Science; American Heart Association Council on Cardiovascular Disease in the Young; American Heart Association Council on Epidemiology and Prevention; American Heart Association Council on Nutrition, Physical Activity and Metabolism; American Heart Association Council on High Blood Pressure Research; American Heart Association Council on Cardiovascular Nursing; American Heart Association Council on the Kidney in Heart Disease; Interdisciplinary Working Group on Quality of Care and Outcomes Research: Cardiovascular risk reduction in high-risk pediatric patients: a scientific statement from the American Heart Association Expert Panel on Population and Prevention Science; the Councils on Cardiovascular Disease in the Young, Epidemiology and Prevention, Nutrition, Physical Activity and Metabolism, High Blood Pressure Research, Cardiovascular Nursing, and the Kidney in Heart Disease; and the Interdisciplinary Working Group on Quality of Care and Outcomes Research: endorsed by the American Academy of Pediatrics. Circulation 114: 2710-2738, 2006.

14. Wilson AC, Schneider MF, Cox C, Greenbaum LA, Saland J, White CT, Furth S, Warady BA and Mitsnefes MM: Prevalence and correlates of multiple cardiovascular risk factors in children with chronic kidney disease. Clin J Am Soc Nephrol 6: 2759-2765, 2011.

15. Kaidar M, Berant M, Krauze I, Cleper R, Mor E, Bar-Nathan N and Davidovits M: Cardiovascular risk factors in children after kidney transplantation - from short-term to long-term follow-up. Pediatr Transplant 18: 23-28, 2014.

16. Parker ED, Sinaiko AR, Kharbanda EO, Margolis KL, Daley MF, Trower NK, Sherwood NE, Greenspan LC, Lo JC, Magid DJ, et al: Change in weight status and development of hypertension. Pediatrics 137: e20151662, 2016.

17. Matteucci MC, Chinali M, Rinelli G, Wühl E, Zurowska A, Charbit M, Pongiglione G and Schaefer F; ESCAPE Trial Group: Change in cardiac geometry and function in CKD children during strict BP control: A randomized study. Clin J Am Soc Nephrol 8: 203-210, 2013.

18. Kupferman JC, Aronson Friedman L, Cox C, Flynn J, Furth S, Warady B and Mitsnefes M; CKiD Study Group: BP control and left ventricular hypertrophy regression in children with CKD. J Am Soc Nephrol 25: 167-174, 2014.

19. Brady TM, Schneider MF, Flynn JT, Cox C, Samuels J, Saland J, White CT, Furth S, Warady BA and Mitsnefes M: Carotid intimamedia thickness in children with CKD: Results from the CKiD study. Clin J Am Soc Nephrol 7: 1930-1937, 2012.

20. Kogon AJ, Pierce CB, Cox C, Brady TM, Mitsnefes MM, Warady BA, Furth SL and Flynn JT: Nephrotic-range proteinuria is strongly associated with poor blood pressure control in pediatric chronic kidney disease. Kidney Int 85: 938-944, 2014.

21. Furth SL, Abraham AG, Jerry-Fluker J, Schwartz GJ, Benfield M, Kaskel F, Wong C, Mak RH, Moxey-Mims M and Warady BA: Metabolic abnormalities, cardiovascular disease risk factors, and GFR decline in children with chronic kidney disease. Clin J Am Soc Nephrol 6: 2132-2140, 2011.

22. Barletta GM, Flynn J, Mitsnefes M, Samuels J, Friedman LA, $\mathrm{Ng}$ D, Cox C, Poffenbarger T, Warady B and Furth S: Heart rate and blood pressure variability in children with chronic kidney disease: A report from the CKiD study. Pediatr Nephrol 29: 1059-1065, 2014.

23. Sinha MD, Gilg JA, Kerecuk L and Reid CJ; British Association for Paediatric Nephrology: Progression to hypertension in nonhypertensive children following renal transplantation. Nephrol Dial Transplant 27: 2990-2996, 2012. 
24. Balzano R, Lindblad YT, Vavilis G, Jogestrand T, Berg UB and Krmar RT: Use of annual ABPM, and repeated carotid scan and echocardiography to monitor cardiovascular health over nine yr in pediatric and young adult renal transplant recipients. Pediatr Transplant 15: 635-641, 2011

25. Reiss AB, Voloshyna I, De Leon J, Miyawaki N and Mattana J: Cholesterol Metabolism in CKD. Am J Kidney Dis 66: 1071-1082, 2015.

26. Kidney Disease: Improving Global Outcomes (KDIGO) Lipid Work Group: KDIGO Clinical Practice Guideline for Lipid Management in Chronic Kidney Disease. Kidney Inter Suppl 3: 259-305, 2013. http://www.kdigo.org/clinical_practice_guidelines/Lipids/ KDIGO\%20Lipid\%20Management\%20Guideline\%202013.pdf.

27. Hartiala O, Magnussen CG, Kajander S, Knuuti J, Ukkonen H, Saraste A, Rinta-Kiikka I, Kainulainen S, Kähönen M, HutriKähönen N, et al: Adolescence risk factors are predictive of coronary artery calcification at middle age: The cardiovascular risk in young Finns study. J Am Coll Cardiol 60: 1364-1370, 2012.

28. Warady BA, Abraham AG, Schwartz GJ, Wong CS, Muñoz A, Betoko A, Mitsnefes M, Kaskel F, Greenbaum LA, Mak RH, et al: Predictors of rapid progression of glomerular and nonglomerular kidney disease in children and adolescents: The chronic kidney disease in children (CKiD) cohort. Am J Kidney Dis 65: 878-888, 2015

29. Wong CJ, Moxey-Mims M, Jerry-Fluker J, Warady BA and Furth SL: CKiD (CKD in children) prospective cohort study: A review of current findings. Am J Kidney Dis 60: 1002-1011, 2012.

30. Silverstein DM, Mitchell M, LeBlanc P and Boudreaux JP: Assessment of risk factors for cardiovasuclar disease in pediatric renal transplant patients. Pediatr Transplant 11: 721-729, 2007.

31. Khurana M and Silverstein DM: Etiology and management of dyslipidemia in children with chronic kidney disease and end-stage renal disease. Pediatr Nephrol 30: 2073-2084, 2015.

32. Mak RH: Insulin and its role in chronic kidney disease. Pediatr Nephrol 23: 355-362, 2008

33. American Diabetes Association: Diagnosis and classification of diabetes mellitus. Diabetes Care 34 (Suppl 1): S62-S69, 2011.

34. Hjelmesaeth J, Hartmann A, Leivestad T, Holdaas H, Sagedal S, Olstad $\mathrm{M}$ and Jenssen T: The impact of early-diagnosed new-onset post-transplantation diabetes mellitus on survival and major cardiac events. Kidney Int 69: 588-595, 2006.

35. Canpolat N, Caliskan S, Sever L, Guzeltas A, Kantarci F, Candan C, Civilibal M, Kasapcopur O and Arisoy N: Glucose intolerance: Is it a risk factor for cardiovascular disease in children with chronic kidney disease? Pediatr Nephrol 27: 627-635, 2012

36. Lai HL, Kartal J and Mitsnefes M: Hyperinsulinemia in pediatric patients with chronic kidney disease: The role of tumor necrosis factor-alpha. Pediatr Nephrol 22: 1751-1756, 2007

37. Kutuby F, Wang S, Desai C and Lerma EV: Anemia of chronic kidney disease. Dis Mon 61: 421-424, 2015

38. Padhi S, Glen J, Pordes BA and Thomas ME; Guideline Development Group: Management of anaemia in chronic kidney disease: Summary of updated NICE guidance. BMJ 350: h2258, 2015.

39. Kidney Disease: Improving Global Outcomes (KDIGO) Anemia Work Group. KDIGO Clinical Practice Guideline for Anemia in Chronic Kidney Disease. Kidney Inter Suppl 2: 279-335, 2012. http://www.kdigo.org/clinical_practice_guidelines/pdf/KDIGOAnemia\%20GL.pdf.

40. Krischock LA, van Stralen KJ, Verrina E, Tizard EJ, Bonthuis M, Reusz G, Hussain FK, Jankauskiene A, Novljan G, SpasojevićDimitrijeva B, et al; ESPN/ERA-EDTA Registry: Anemia in children following renal transplantation-results from the ESPN/ ERA-EDTA Registry. Pediatr Nephrol 31: 325-333, 2016.

41. Gupta J, Mitra N, Kanetsky PA, Devaney J, Wing MR, Reilly M, Shah VO, Balakrishnan VS, Guzman NJ, Girndt M, et al; CRIC Study Investigators: Association between albuminuria, kidney function, and inflammatory biomarker profile in CKD in CRIC Clin J Am Soc Nephrol 7: 1938-1946, 2012.

42. Ece A, Gürkan F, Kervancioğlu M, Kocamaz H, Güneş A, Atamer Y, Selek S and Yolbas I: Oxidative stress, inflammation and early cardiovascular damage in children with chronic renal failure. Pediatr Nephrol 21: 545-552, 2006

43. Matteucci MC, Wühl E, Picca S, Mastrostefano A, Rinelli G, Romano C, Rizzoni G, Mehls O, de Simone G and Schaefer F; ESCAPE Trial Group: Left ventricular geometry in children with mild to moderate chronic renal insufficiency. J Am Soc Nephrol 17: 218-226, 2006.
44. Sebeková K, Podracká L, Heidland A and Schinzel R: Enhanced plasma levels of advanced glycation end products (AGE) and pro-inflammatory cytokines in children/adolescents with chronic renal insufficiency and after renal replacement therapy by dialysis and transplantation - are they inter-related? Clin Nephrol 56: S21-S26, 2001.

45. Wong CS, Pierce CB, Cole SR, Warady BA, Mak RH, Benador NM, Kaskel F, Furth SL and Schwartz GJ; CKiD Investigators: Association of proteinuria with race, cause of chronic kidney disease, and glomerular filtration rate in the chronic kidney disease in children study. Clin J Am Soc Nephrol 4: 812-819, 2009.

46. Agrawal V, Marinescu V, Agarwal M and McCullough PA Cardiovascular implications of proteinuria: An indicator of chronic kidney disease. Nat Rev Cardiol 6: 301-311, 2009.

47. Stehouwer CD and Smulders YM: Microalbuminuria and risk for cardiovascular disease: Analysis of potential mechanisms. J Am Soc Nephrol 17: 2106-2111, 2006.

48. Fathallah-Shaykh SA, Flynn JT, Pierce CB, Abraham AG, BlydtHansen TD, Massengill SF, Moxey-Mims MM, Warady BA, Furth SL and Wong CS: Progression of pediatric CKD of nonglomerular origin in the CKiD cohort. Clin J Am Soc Nephrol 10: 571-577, 2015.

49. Ponticelli $\mathrm{C}$ and Graziani G: Proteinuria after kidney transplantation. Transpl Int 25: 909-917, 2012

50. Seeman T, Dusek J, Vondrák K, Spatenka J and Feber J: Profiling proteinuria in children after renal transplantation. Pediatr Nephrol 24: 2439-2444, 2009.

51. Blau JE and Collins MT: The PTH-Vitamin D-FGF23 axis. Rev Endocr Metab Disord 16: 165-174, 2015.

52. Chonchol M, Greene T, Zhang Y, Hoofnagle AN and Cheung AK Low vitamin D and high fibroblast growth factor 23 serum levels associate with infectious and cardiac deaths in the HEMO Study. J Am Soc Nephrol 27: 227-237, 2016.

53. Patange AR, Valentini RP, Gothe MP, Du W and Pettersen MD Vitamin D deficiency is associated with increased left ventricular mass and diastolic dysfunction in children with chronic kidney disease. Pediatr Cardiol 34: 536-542, 2013.

54. Mann MC, Hobbs AJ, Hemmelgarn BR, Roberts DJ, Ahmed SB and Rabi DM: Effect of oral vitamin D analogs on mortality and cardiovascular outcomes among adults with chronic kidney disease: A meta-analysis. Clin Kidney J 8: 41-48, 2015.

55. Scialla JJ, Xie H, Rahman M, Anderson AH, Isakova T, Ojo A, Zhang X, Nessel L, Hamano T, Grunwald JE, et al; Chronic Renal Insufficiency Cohort (CRIC) Study Investigators: Fibroblast growth factor-23 and cardiovascular events in CKD. J Am Soc Nephrol 25: 349-360, 2014.

56. Brandenburg VM, Kleber ME, Vervloet MG, Larsson TE, Tomaschitz A, Pilz S, Stojakovic T, Delgado G, Grammer TB, Marx N, et al: Soluble klotho and mortality: The Ludwigshafen Risk and Cardiovascular Health Study. Atherosclerosis 242: 483-489, 2015.

57. Navarro-González JF, Donate-Correa J, Muros de Fuentes M, Pérez-Hernández H, Martínez-Sanz R and Mora-Fernández C: Reduced Klotho is associated with the presence and severity of coronary artery disease. Heart 100: 34-40, 2014.

58. Kumar J, McDermott K, Abraham AG, Friedman LA, Johnson VL, Kaskel FJ, Furth SL, Warady BA, Portale AA and Melamed ML: Prevalence and correlates of 25-hydroxy vitamin D deficiency in the Chronic Kidney Disease in Children (CKiD) cohort. Pediatr Nephrol 31: 121-129, 2016.

59. Wesseling-Perry K, Pereira RC, Tseng CH,Elashoff R,Zaritsky JJ, Yadin O, Sahney S, Gales B, Jüppner H and Salusky IB: Early skeletal and biochemical alterations in pediatric chronic kidney disease. Clin J Am Soc Nephrol 7: 146-152, 2012.

60. Portale AA, Wolf M, Jüppner H, Messinger S, Kumar J, Wesseling-Perry K, Schwartz GJ, Furth SL, Warady BA and Salusky IB: Disordered FGF23 and mineral metabolism in children with CKD. Clin J Am Soc Nephrol 9: 344-353, 2014

61. Wan M, Smith C, Shah V, Gullet A, Wells D, Rees L and Shroff R Fibroblast growth factor 23 and soluble klotho in children with chronic kidney disease. Nephrol Dial Transplant 28: 153-161, 2013.

62. Sawires HK, Essam RM, Morgan MF and Mahmoud RA: Serum klotho: Relation to fibroblast growth factor-23 and other regulators of phosphate metabolism in children with chronic kidney disease. Nephron 129: 293-299, 2015. 